\title{
LA NOMADOLOGÍA DE DELEUZE-GUATTARI ${ }^{1}$
}

\author{
Autor: Paulo Domenech Oneto ${ }^{2}$ \\ Traducción: Carolina Villada Castro ${ }^{3}$
}

EL capítulo o "meseta” 12 del libro Mil Mesetas, de Gilles Deleuze y Félix Guattari -publicado en 1980 como la segunda parte de Capitalismo y Esquizofrenia (dando secuencia al Anti- Edipo, de nueve años atrás) - es titulado "Tratado de Nomadología: la máquina de guerra". Con el ejemplo de las demás mesetas que componen la obra, ese título está precedido por un número, que nada tiene que ver con la numeración de los capítulos. Se trata de un año o período histórico, al que cada uno de los temas

1 Este texto fue escrito originalmente en 1990. Intenté hacer algunas alteraciones, pero creo que, a pesar de todo, continúa reflejando mis preocupaciones de entonces, que eran las siguientes: ofrecer una reseńa explicativa del capítulo "Tratado de Nomadología” de Deleuze-Guattari e intentar situarlo en el ámbito de la discusión ontológica acerca de la inmanencia, tema de mi disertación de maestría en aquella época.

$N$. del T. Publicado inicialmente en portugués en Revista lugar comum, No23-24, Rio de janeiro: Uninômade Brasil, pp.147-161, a cuyos editores agradecemos autorizar esta traducción al español. Resulta importante indicar también que la nomadología no sólo concierne a la problemática del texto; sino al agenciamiento en juego de la revista en la que apareció, articulada al proyecto de construcción de una red internacional de universidades nómadas para resistir al capitalismo cognitivo, indicando no sólo la pertinencia del texto para nuestros contextos contemporáneos sino las herramientas por usar que nos dispone.

2 Doctor en Filosofía, profesor de la Escuela de comunicación de la UFRJ-Rio de Janeiro, Brasil. Otras de sus publicaciones son: "Spinoza e a passagem ao político". En: Revista Conatus (UECE. Online), v. 1, p. 1-7, 2007; "Géophilosophie et anthropophagie: esquisse de lecture deleuzo-guattarienne de la pensée moderniste d'Oswald de Andrade”. En: Ana Kiffer; Tatiana Roque; Jean-François Nordmann; Paulo Oneto. (Org.). Brésil / Europe: repenser le mouvement anthropophagique. Paris: Collège International de Philosophie, 2008, v. 60, p. 75-79; ABREU, O.; ONETO, P. G. DOMENECH. "Deleuze e a crítica da verdade”. En: O Que nos Faz Pensar (PUCRJ), v. 35, p. 149-167, 2015.

3 Magíster en Estudios de la traducción de la Universidad Federal de Santa Catarina-PGET Brasil. Profesional en Filosofía de la Universidad de Antioquia Colombia.

Correo electrónico: carolina.villadacastro@gmail.com. 
abordados en el libro está relacionado directa o indirectamente. En el caso de este "tratado", cuyo título es, al mismo tiempo, una referencia a los nómadas y un juego de palabras con la monadología leibniziana, el número es 1227. ¿Pero qué extraña fecha es esta? ¿Y de qué trata exactamente el capítulo en cuestión?

El año es la fecha de la muerte de Gengis Khan, cuyo nombre real era Temujin y que se hizo jefe (khan) de los guerreros mongoles en aquel distante siglo XIII. Temujin tuvo una infancia difícil, pero fue lo bastante hábil para hacerse "jefe universal" de las tribus nómadas de toda Asia, formadas por pueblos de etnias diferentes, llevándolos a ocupar un área que se extendía de Pekín (China) hasta la región del Volga (Rusia). Pese a los relatos de crueldad que ilustran la acción de Gengis Khan, fue esa dominación la que garantizó un periodo de paz para los pueblos turcos y mongoles (entre otros), al abrir espacio para que ellos pudieran circular sin la amenaza de ser diezmados o simplemente incorporados a los reinos vecinos.

La pregunta más importante de este capítulo gira precisamente en torno de ese tipo de acción nómada que, como el segundo axioma del tratado propuesto dejará claro, es distinta de la acción de una institución militar. Gengis Khan se vuelve, así, un nombre emblemático en medio de la argumentación general de Deleuze-Guattari (o Deleuze y Guattari para los amantes de la individuación), en la medida en que, en ese personaje histórico, aparecen asociados los problemas del nomadismo y del espíritu guerrero. El tema del capítulo aparece, entonces, bien delineado. Lo que está en juego es la elaboración de una especie de paradigma que es, al mismo tiempo, político, sociocultural y epistemológico: el paradigma de la máquina de guerra. Pero la "máquina de guerra" de Deleuze-Guattari tiene muy poco o nada que ver con el sentido común dado al término. No se trata de hablar del aparato militar que un Estado, reino o imperio es capaz de construir para hacer la guerra contra sus enemigos internos o externos, sino de mostrar que una máquina de guerra es siempre (por definición) exterior a las diversas formas de Estado surgidas a lo largo de la historia. Estas serían, en rigor, manifestaciones de otro paradigma, correlato del primero y con el que la máquina de guerra mantendría una relación de 
oposición, permanente tensión, competencia, atracción mutua, pero sin complementariedad: el paradigma del aparato de Estado. Pero entonces ca qué acción guerrera estaría real y directamente asociada? Surge así el detalle crucial que explica el título del capítulo. Para comprender la máquina de guerra es necesario hablar de nomadismo, pues como el axioma II ya mencionado afirma: "los nómadas han creado la máquina de guerra” (DELEUZE, 2004: 390).

Los asuntos de $(\mathrm{I})^{4}$ la exterioridad de la máquina de guerra con respecto a las formas políticas, socioculturales o epistemológicas de tipo-Estado (aparatos de Estado), (II) su articulación inmediata con el nomadismo y (III) con su "competidor más próximo" (la metalurgia) constituyen los tres axiomas del tratado de nomadología propuesto. Un apunte importante: a un lector más desprevenido o apresurado podrá parecerle que la argumentación está montada a partir de relatos históricos y que los términos utilizados por los autores designan entidades empíricas situadas a lo largo de esa historia -el Estado, la guerra, el nómada, la metalurgia, etc. El objetivo de mi comentario es en este sentido triple: a) mostrar que este no es absolutamente el caso -al contrario, los ejemplos son modos de probar la validez de los axiomas, los cuales tratan de paradigmas para la compresión de los fenómenos más diversos; b) evaluar los ejemplos dados, añadiendo de paso algunos nuevos ejemplos que corroboren los axiomas; c) indicar la importancia de los dos paradigmas para pensar la política.

\section{Dos paradigmas}

En realidad, el extraño tratado propuesto por Deleuze y Guattari se articula, al menos aparentemente, de un modo bastante tradicional, es decir, a partir de axiomas y proposiciones, como en el caso de una obra bastante querida por Deleuze: la Ética de Spinoza. Encontramos en el texto un análisis minucioso poblado de ejemplos que surgen y se desarrollan a partir

$4 \quad$ N. del T. Esta numeración corresponde a la que utilizan Deleuze-Guattari en: "1227. Tratado de nomadología: La máquina de guerra”, En: Mil Mesetas, Capitalismo y esquizofrenia. José Vásquez Pérez y Umberlina Larraceleta (trads.). Pre-textos: Valencia, 2004, pp. 359- 432. 
de tres axiomas. Como ya se dijo, el Axioma II complementa la referencia a Gengis Khan, enfatizando dos puntos esenciales de la propuesta de los filósofos: 1) la relación entre nomadismo y máquina de guerra y 2) la diferencia radical entre la dinámica que anima este paradigma guerrero y la acción centralizada de un Estado con su poder militar. Sin embargo, antes de llegar a él, es necesario abordar el axioma número I que orienta toda la propuesta micropolítica de Deleuze-Guattari, yendo incluso más allá de Mil Mesetas.

El axioma en cuestión afirma que "la máquina de guerra es exterior al Estado" (DELEUZE, 2004: 240) Como cualquier otro axioma, la aserción aquí carece de demostración, en este caso por tratarse de un raciocinio por definición. Lo curioso y complejo aquí es que las definiciones de los dos conceptos, que designan paradigmas de acción política, sociocultural o de pensamiento, no son dadas por separado del análisis general ni tampoco de los ejemplos. Estos, además, según Deleuze-Guattari son empleados para reconocer (no para demostrar o incluso comprobar) la validez del axioma. Es a partir de una serie de proposiciones, intercaladas por problemas, que se encuentra la llave para la comprensión de lo que cada uno de los dos paradigmas recubre. La primera proposición es particularmente importante para situar al lector. Dice que la exterioridad de las máquinas de guerra es testimoniada por la mitología, la epopeya, el drama y los juegos. Es de ese modo que, gradualmente, se van delineando los principales aspectos de cada uno de los paradigmas.

La mitología indoeuropea, tal como fue analizada por Georges Dumézil, sirve para proporcionar las líneas generales que integran la comprensión de los conceptos-paradigmas discutidos. En esta mitología, los fenómenos de la dominación y la soberanía se caracterizan por tomar como modelo dos divinidades. De un lado está la figura del rey-mago, déspota, inspirada por Varuna. Por otro lado, se encuentra la figura del sacerdote-jurista y legislador, que encuentra correspondencia en Mitra. La noción de soberanía y su práctica necesitan de esos dos elementos que se alternan, rivalizan y se complementan. Juntos traducen el doble movimiento que hace emerger y mantiene el aparato de Estado. Este paradigma es, por tanto, el resultado de una doble articulación que lo constituye como un estrato, una forma 
más o menos cerrada, con una zona de interioridad que permite distinguir un centro. Por eso mismo, el aparato que se forma a partir de esos dos movimientos -cuya finalidad es asegurar las condiciones para dominar, sea por medio de leyes o de amenazas- no debe ser confundido con un aparato que incluye necesariamente una acción de guerra. Al contrario, el lugar de la guerra es siempre derivado en el aparato de Estado. Para dominar, basta disponer de mecanismos de amenaza o de represión directa, cuya violencia nunca es diseminada (como en el caso de una guerra), o entonces mantener un ejército, cuya función es mantener la guerra en suspenso, como una posibilidad en situaciones-límite.

Por otro lado, la máquina de guerra aparece en Indra, divinidad que se opone tanto a Varuna como a Mitra por ser algo del orden de lo efímero, siempre listo para una acción sin preparación previa. Su diferencia reside en el hecho de aparecer como velocidad pura, como pura exterioridad, sin medida común con las otras dos instancias, irreducible a ellas, pero sin traducirse bajo la forma de una tercera instancia o una vía alternativa. Así, Indra es la potencia de metamorfosis que no cesa de conmover las instancias-entidades formadas. En cuanto estas últimas son unidades, Indra corresponde a la pura multiplicidad que circula en los intersticios de esas unidades dominantes (Mitra y Varuna). Es por esto que no tendría sentido esperar la substitución del aparato de Estado por la máquina de guerra en una coyuntura dada: "la máquina de guerra es de otra especie, de otra naturaleza, de otro origen que el aparato de Estado" (DELEUZE, 2004: 360)

En el campo de la epopeya, el drama o los juegos, Deleuze y Guattari buscan nuevas herramientas para definir mejor los dos paradigmas y, así, hacer más evidente el axioma I. Surgen entonces Aquiles y Ulises, los reyes de Shakespeare, el ajedrez o el Go. En los dos primeros ejemplos, el mayor esfuerzo de los autores reside en proporcionar elementos que permitan despejar la frecuente confusión, hecha entre la potencia extrínseca que es característica de la máquina de guerra y el uso de la violencia o la militarización, típicas del aparato de Estado. Sin embargo, la potencia nunca es una relación dinámica entre polos de poder. La potencia no es algo que se posea, sino algo que ejercemos siempre, de uno u otro modo. El proceso de aceleración continua y los secretos de 
la acción guerrera no pueden, por tanto, ser del mismo orden de la alta velocidad de la acción policial o militar, cuyos secretos son de interés público. Una pandilla digna de ese nombre se mantiene, por definición, como una pandilla de calle, vagabunda; así como una tropa policial debe aspirar a ser una tropa de élite.

El guerrero aristocrático Aquiles es separado de su potencia de actuar en el momento en que es acorralado entre los dos polos de poder griego, primero aceptando ser soldado de Agamenón y, después, dejando sus armas para el hombre de Estado Ulises. En el teatro de Shakespeare, la violencia, los crímenes y las perversiones de la realeza son apenas medios para la conquista de un lugar. El personaje de Kleist, Michael Kohlhaas, intenta contener su furia tras la intervención de Lutero y acaba transformándose en un simple insurrecto condenado a morir en la lucha contra los núcleos de poder germánico. Entre el ajedrez y el Go chino encontramos una nueva diferencia: en el primer juego, las piezas tienen cualidades y valores determinados a priori (funciones militares) mientras que en el Go los peones son extrínsecos, dependen de la situación en la que se encuentren.

Los ejemplos posibles son muchos... sin embargo, lo que importa es el surgimiento de un problema que obliga a Deleuze y Guattari a presentar dos nuevas proposiciones, que no son más que dos nuevos campos de análisis con ejemplos. El problema I es enunciado de la siguiente manera: "¿Existe algún medio de conjurar la formación de un aparato de Estado (o de sus equivalentes en un grupo)?" (DELEUZE, 2004: 364). Seguido por las siguientes proposiciones (II y III): la exterioridad de la máquina de guerra es probada también por la etnología; esa misma exterioridad también es corroborada por la epistemología. Además, acontece que el análisis epistemológico acaba por conducir a otro problema (II) que envuelve la naturaleza propia del pensamiento "¿Existe un medio de sustraer el pensamiento al modelo de Estado?” (DELEUZE, 2004: 379). Este problema permite que sea convocado un último ejemplo, capaz especialmente de probar la situación de exterioridad de la máquina de guerra. Se trata de la proposición IV, que busca extraer de un análisis de las imágenes que el pensamiento elabora acerca de sí mismo (imágenes sobre lo que es pensar), una nueva ilustración para el axioma presentado. 
De este modo, se afirma que "La exterioridad de la máquina de guerra es confirmada finalmente por la noología” (DELEUZE, 2004: 379)

\section{Etnología, epistemología, noología}

Según Deleuze y Guattari tanto la etnología de Pierre Clastres como un análisis epistemológico fino, como el realizado por Michel Serres, pueden hacer ver mejor la existencia del paradigma guerrero que traduce más que un "lado de afuera" del aparato de Estado- la pura forma de exterioridad $^{5}$. Sin embargo, el mejor ejemplo vendrá de un análisis del propio acto de pensar (noología) que puede ser encarado como un acto natural -ejercicio de una facultad apta para conquistar lo verdadero como elemento esencial del pensamiento- o, al contrario, como planteamiento de problemas de mayor o menor importancia, cuyas soluciones dependen del modo de problematización.

En las áreas de etnología y epistemología, la tensión entre máquina de guerra y aparato de Estado vuelve a surgir en términos de la oposición entre bandos y forma política "estatal" o entre ciencias oficiales y menores. Tomando como punto de partida los análisis de Clastres sobre las sociedades llamadas primitivas, Deleuze y Guattari buscan mostrar que la no formación de un Estado por parte de algunas sociedades está lejos de indicar algún atraso en su proceso de evolución natural. Más allá de combatir ese tipo de evolucionismo, que ve en la forma-Estado un desdoblamiento natural, dándose en función del elevado nivel de desarrollo económico de las sociedades (primera tesis), Clastres indaga si no habría justamente un esfuerzo (afortunado) de conjuración del Estado en esas sociedades (segunda tesis).

Un punto importante surge en el pasaje entre las dos tesis. Consiste en la afirmación de que un Estado no se define por la existencia de uno o más jefes. Lo que lo define es el movimiento de perpetuación o conservación

5 "No basta con afirmar que la máquina es exterior al aparato, hay que llegar a pensar la máquina de guerra como algo que es una pura forma de exterioridad, mientras que el aparato de Estado constituye la forma de interioridad que habitualmente tomamos como modelo, o según la cual pensamos habitualmente" (DELEUZE, 2004: 362) 
de órganos de poder (DELEUZE, 2004: 381). La preocupación del aparato de Estado es precisamente esta: conservar. La guerra en las sociedades primitivas es hecha, de acuerdo con la segunda tesis de Clastres, para impedir la formación de un Estado. Sirve para mantener dispersos los varios segmentos involucrados en la lucha, sin principio de unificación. Así, no es apenas el Estado el que se erige contra la guerra, como en el contractualismo hobbesiano. En sentido fuerte, la guerra es hecha contra la forma-Estado.

Las tesis de Clastres son importantes para mostrar ese aspecto de la exterioridad de la máquina de guerra, a saber, estos dos aspectos: el hecho de que ella no representa un estadio más atrasado (provisional) o más avanzado con relación al aparato de Estado, sino también el hecho de utilizarse justamente la guerra para conjurar la formación de ese aparato. Por otro lado, el etnólogo parece contentarse con una división casi purista entre sociedades de Estado y sociedades "sin-y-hasta-contra-el-Estado". Además, importa detectar las fuerzas que llevan a la formación de algo como un aparato de Estado y tratar su relación con fuerzas que resisten a ese proceso o que incluso conducen a una disolución de los Estados. Sin un análisis de ese tipo, la exterioridad formal o paradigmática de la máquina de guerra es vista como una exterioridad de hecho, propia de un tipo de organización apenas diferente (tal vez mejor), independiente. Pero siempre hay tendencia a la formación de algo como un Estado. Del mismo modo en que este está siempre conmovido por fuerzas individuales y sociales que nunca son completa o fácilmente capturables "el Estado siempre ha estado en relación con un afuera, y no se puede concebir independientemente de esta relación" (DELEUZE, 2004: 367).

El Estado es la soberanía que está siempre lista para apropiarse de la potencia con el objetivo de interiorizarla bajo la forma de un poder jerarquizado. La forma-Estado tiene una fuerte tendencia a reproducirse solicitando el reconocimiento público de sus derechos, como una necesidad -la necesidad de la Ley. Pero la máquina de guerra como pura forma de exterioridad, sólo aparece y existe en proceso, en sus metamorfosis, como un flujo con sus reglas inmanentes: en las informaciones que circulan en la internet, en un movimiento religioso o en una manifestación de calle, en las pandillas, en los movimientos de los sin-tierra, sin-techo, sin-voto, sin-formación, entre 
otros $^{6}$. Su apropiación o eliminación por los aparatos de Estado siempre es inminente, pero acaba implicando la abertura para nuevos flujos.

Por tanto, el problema del análisis de Clastres es el siguiente: sugerir una independencia entre los dos paradigmas, cuando lo que hay es coexistencia y concurrencia dentro de un perpetuo campo de interacciones. En este sentido, el ejemplo epistemológico tal vez sea más adecuado para mostrar esa doble relación de coexistencia y competencia entre los paradigmas, alejando cualquier hipótesis purista, de una sociedad salvaje o nativista, que podría volver la máquina de guerra una especie de ideal transformando, por ejemplo, Gengis Khan, Antônio Conselheiro ${ }^{7}$, desobedientes civiles, amantes del funk o traficantes en héroes.

El caso de lo que Deleuze denomina imágenes del pensamiento actuando en la propia génesis de las ciencias- es aún más interesante por implicar directamente a los propios Deleuze y Guattari. A final de cuentas, al escribir "mesetas" en lugar de capítulos -justamente para destacar el carácter pragmático del libro, que no requiere una lectura sistemática o secuencial, sino que reclama un abordaje "por el medio", con cada uno de los temas remitiendo a una región continua de intensidades, sin subordinación temática en la dirección de un punto culminante (DELEUZE, 2004: 26). Los dos autores destacan la existencia de una máquina de guerra en la propia actividad de pensar, abriendo campo para un diagnóstico acerca de los umbrales a partir de los cuales contenidos y formas de pensamiento tienden a hacerse sedentarios y a hacerse rígidos. Desde entonces, el propio Mil Mesetas aparece como una tentativa de contacto con la exterioridad, convocando no tanto a una interpretación como a un uso de los conceptos tratados en una situación de combate.

$6 \quad N$. del T. Serie de movimientos y movilizaciones viejas y nuevas transversales al campo y a las ciudades brasileras, cuyas reivindicaciones van desde la reforma Agraria, la reforma urbana hasta las condiciones dignas de vivienda en el contexto contemporáneo de especulación financiera. La articulación entre estos movimientos y movilizaciones compone toda una cartografía de las resistencias contemporáneas brasileras y los agenciamentos nómadas que justifican su alusión.

$7 \quad$ N. del T. Líder rebelde y místico bahiano, nordeste brasilero, destacado durante la Guerra de Canudos s. XIX en la que indígenas, esclavos y campesinos libertos se oponen a la crisis social y económica debida a los latifundios improductivos, el desempleo y las sequías permanentes, exterminados por ejércitos republicanos. 
En realidad, el modelo "estatal" presupone una evolución de las formas de racionalidad que acompaña la propia variación de la forma- Estado. Contra la reducción o la subordinación del pensamiento a ese modelo, Deleuze y Guattari buscan enfatizar la presencia de un devenir-problematizador que no deja de amenazar todo aquello que es del orden del saber como conquista o posesión, ocupando un lugar central en la cultura. Ese pensamiento "guerrero", por así llamarlo, hace surgir en el campo epistemológico un tipo de ciencia nómada o "menor". La noología, como el estudio de las imágenes que un pensamiento elabora al respecto de sí mismo, es una invención de Deleuze-Guattari que nos ayuda a comprender mejor la manera en que la epistemología también puede probar la celebrada exterioridad de la máquina de guerra. Mediante los trabajos de Michel Serres, por ejemplo, es posible delimitar dos modos de formalización bastante distintos, caracterizando, de un lado, una ciencia real o imperial, y, de otro lado, una ciencia nómada. En el primer tipo de ciencia, se trata de un saber que pretende emerger de un pensamiento afirmativo de universalidad y afinidad con lo verdadero. Ya en el segundo tipo, estamos ante una ciencia de difícil clasificación, fruto de un pensamiento informe que, por eso mismo, nunca se presta a servir a un Estado.

Las ciencias oficiales poseen su estatuto bien definido, funcionando en provecho del Estado, de quien obtiene su respaldo. Su modo de formalización presenta cuatro características básicas: 1) entiende la realidad como un "sólido", pudiendo incluso ser definida como una teoría de sólidos; 2) pretende construir modelos estables, homogéneos, eternos, siempre a la caza de invariantes; 3) hace de la realidad algo plenamente mensurable, proponiendo un espacio lineal, cerrado, en el que vamos de rectas a paralelas -espacio estriado (métrico), en el que su carácter mensurable prepara para una ocupación sedentaria; 4) es un modelo teoremático de ciencia, es decir, basado en una racionalidad presupuesta, para la cual los problemas no pasan de obstáculos a ser superados rumbo al elemento esencial.

En contrapartida, los nómadas practican la ciencia de una manera que supone otra concepción, excéntrica, pero próxima de lo que denominamos artes. Su modo de formalización es vago. Sus cuatro características, por oposición al modelo del aparato de Estado son: 1) la realidad es vista como un conjunto de flujos (devenires), proporcionando un modelo hidráulico; 
2) su materia es heterogénea, sin forma preestablecida; 3) esto implica un modelo de torbellino, operando en un espacio visto como liso (topológico) que es ocupado sin ser numerado o medido, que se delinea en función de la distribución de flujos; 4) se constituye como un modelo problemático, es decir, como un modelo para el cual pensar es problematizar sin que la razón posea nada de derecho. Así, mientras el aparato de Estado limita el elemento-problema para subordinarlo a un teorema con sus proposiciones demostrables, la máquina de guerra es el paradigma de la experimentación. En ella todo conocimiento es "afectivo", en el sentido que las figuras que emergen sólo tienen valor en función de lo que las afecta. Cada figura designa, por tanto, un acontecimiento y no una esencia.

La crítica dirigida al modelo epistemológico del Estado es una crítica a los modelos euclidiano e hilemórfico, el primero por abstraer un espacio vuelto independiente, el segundo por presuponer una forma, suponiéndola inalterable ante una materia homogénea. Además, en el paradigma de la máquina de guerra el espacio es vectorial y las formas se dan junto con el movimiento permanente de una materia heterogénea. Desde el punto de vista noológico, el apoyo que el pensamiento puede encontrar en el Estado -ya que "la forma en que una ciencia, o una concepción de la ciencia, participa en la organización del campo social (...) forma parte de esa misma ciencia" (DELEUZE, 2004: 374), puede incluso ser útil, pero habrá siempre un aspecto que inevitablemente queda "fuera" (bajo la pena de perder vigor), en la medida exacta en que pensar no se hace a partir de un suelo estable con objetivos claros de fijar zonas de actuación privilegiada, por ejemplo para un trabajo o para una afirmación de una posición social: la alianza tan en boga en el Brasil académico de hoy, entre el afán de especialización, titulación y visibilidad mediática ${ }^{8}$.

Es comprensible entonces que la exterioridad noológica de la máquina de guerra se manifieste más por el estilo que por los contenidos o materias tratadas: el aforismo nietzscheano, el concepto como algo que debe ser

$8 \quad N$. del T. Se refieren aquí la formación, titulación y el trabajo en el campo educativo como conductas económicas y economizadas en el contexto contemporáneo debido al capitalismo cognitivo, evento global que ha producido diversas movilizaciones de rechazo en diversos lugares del mundo, incluida la red de universidades nómadas a la que se articuló este texto. 
creado en función de problemas originales que no dejan de imponerse a cada uno de nosotros, forzándonos afectivamente a pensar.

\section{Los tres aspectos de la máquina de guerra}

Esta crítica a un modelo verdadero de pensamiento y a un modelo hilemórfico de ciencia es prolongada por Deleuze y Guattari en una serie de direcciones inusitadas. En todas ellas, podemos decir que lo que está en juego es la indagación por la inmanencia y el nomadismo. Es decir, aquí y allí se trata siempre de rechazar la separación de los paradigmas en regiones compartimentadas enfatizando, al contrario, la tensión, atracción y competencia entre ellos. En ese sentido, no hay dicotomía entre máquina de guerra y aparato de Estado, ni siquiera una posición de trascendencia de uno de los paradigmas o de nosotros y la sociedad en relación con ellos. Se trata siempre de ellos, pero de ellos como acciones posibles ante los devenires que constituyen la vida, aceleraciones y cristalizaciones.

Surge aquí la ocasión para presentar un segundo axioma, complementario al primero y que explica el título del capítulo - "meseta"- tratado: "La máquina de guerra es una invención de los nómadas (en la medida en que es exterior al aparato de Estado y distinta de la institución militar)" (DELEUZE, 2004: 384). En vista de eso, la máquina de guerra nómada tiene tres aspectos: un aspecto espacial- geográfico, uno algebraico y uno afectivo mencionados en el axioma (DELEUZE, 2004: 384).

Las proposiciones de $\mathrm{V}$ a VII trabajan precisamente con esa existencia nómada, que efectúa las condiciones exteriores de la máquina de guerra en el espacio, implicando sus elementos numéricos típicos y valiéndose de las armas que utiliza. Este triple movimiento es el que se traduce en los aspectos espacial-geográfico, algebraico y afectivo mencionados en el axioma.

En términos de espacio geográfico, los autores muestran que el nómada, más que aquel que se desplaza de un territorio a otro, es "desterritorializador". Lo importante de Gengis Khan no sería liderar tribus efectivamente nómadas, sino liderarlas de tal modo que pudiera arrancar 
el territorio ocupado de su sedentarismo. A partir de ahí, las rutas asiáticas dejan de tener un centro. En términos aritméticos las líneas del recorrido son las que dejan de tener un punto cero (de partida) y un punto de llegada -toda trayectoria "se completa" en lo infinitesimal. Los autores también se ocupan de distinguir el nómada de la figura del migrante. Este va siempre de un punto a otro (del Nordeste al sudeste del Brasil, pero en el camino opuesto también, en busca de empleo o de sosiego), mientras que el nómada sólo afirma un desplazamiento durante su movimiento- en un momento Georges Jackson quiere huir de la prisión, pero encuentra un arma... (del mismo modo algunos de los personajes de Wim Wenders...). La dirección del movimiento se da concomitantemente al movimiento, como en el poema de Antonio Machado: "caminante no hay camino... se hace camino al andar".

Aún en el campo numérico, de la aritmética o del álgebra, Deleuze y Guattari destacan una distinción semejante, entre el número numerado (como en una cuenta regresiva) y el número que numera (la cifra). E número numerado es dado de antemano, marcando o demarcando un espacio a ser recorrido, definiendo un espacio estriado con sus números correspondientes. Ya la cifra es como una suma de dinero que es contada al mismo tiempo que nos llega a las manos. Ahí la cuenta es autónoma e inmanente. Cuenta con una levedad que es propia a la levedad de su elemento móvil. Leve, el móvil puede deslazarse en zigzag, sin lugar de llegada, ganando una velocidad que es la marca de la desterritorialización. Pero es por ganar peso que el cuerpo móvil en determinados momentos pierde velocidad y tiende a ser dominado por una fuerza centrípeta, conduciendo a su captura en la interioridad naturalizada del aparato de Estado. Aquí se pueden dar varios ejemplos... el organismo biológico subordinado a la actividad corporal con un "buen funcionamiento" general de los órganos, en nombre de un ideal de vida o de un modo de sobrevivencia; los enclosures en la Inglaterra precapitalista; el intelectual a la espera de un cargo en la burocracia estatal; las minorías defendiendo específicamente "su lugar" en la sociedad; el artista- académico, jefe de escuela; los partidos políticos obedientes al juego político del momento... Pero la velocidad está en el cuerpo sin órganos de Artaud, en la tierra que sólo es marcada por la ocupación, en el intelectual sin rótulo, en la 
minoría cuyas conquistas no implican la formación de una identidad, en el artista sin escuela, en los partidos cuando actúan fuera de una política privilegiada...

La cuestión consiste en saber cuándo el espacio deja de ser soporte para volverse sólo o principalmente territorio. Territorios y reterritorializaciones siempre hay. Sin embargo, para el nómada el territorio es punto de cambio y de pasaje, y, la reterritorialización se da siempre sobre su cuerpo. E cuerpo del nómada y el espacio son indiscernibles, así como número y punto numerado. No podemos siquiera decir que el nómada ocupa un espacio o que el número sirve para indicar un punto o para medir. Ya no podemos decir que vivir, pensar, crear o actuar políticamente sea siquiera próximo a sobrevivir, tener razón, embellecer o distribuir poder para sí y para otros. Se trata de otra cosa...

Esta "otra cosa" tal vez pueda ser explicada por medio de una breve alusión a la proposición VII. En ella son mencionados los "afectos" que constituyen la existencia nómada. Ellos son las armas de la máquina de guerra. El nomadismo inventa la máquina de guerra y tiene sus "afectos" en las armas que esta máquina utiliza. ¿Qué quiere decir esto?

La pregunta remite aquí a los "instrumentos" de los que dispone el nómada. El agenciamiento de cada pieza es el que puede definir lo que irá a hacer: utensilio para un trabajo determinado (en el caso del aparato de Estado) o arma para una acción inmediata. Armas y utensilios dependen de los agenciamientos de deseo que se establecen: las armas están relacionadas con una proyección, los utensilios con una introcepción (posición relacionada con un centro). Un instrumento moldeado según una forma específica, fabricado en serie para el trabajo de los hombres con una finalidad que responde a las necesidades del aparato de Estado, puede transformarse de un momento a otro, en un afecto-arma. Pero si un utensilio comporta mecanismos de proyección que lo abren para un tipo de utilización "afectiva", lo recíproco también vale para el arma del soldado o incluso del militante cuando adquiere un aspecto racional-teleológico de cumplimiento lógico y objetivo de una finalidad. De este modo, está claro que las "armas" aquí no designan necesariamente ametralladoras, 
pistolas o bagatelas de ese género. Al contrario, raramente designan esos objetos. Las manos libres del karate son mucho más "afectos-armas" que los sables de los samuráis y sus caballos.

Las armas de la máquina de guerra son (o se tornan) los "afectos" de los nómadas simplemente porque nunca están sujetos a una acción definida por un centro racional o político, para el cual debe volver su faz. Es claro, que pueden tender a ese centro por fuerza de un agenciamiento, dejando de ser "afectos- armas" y tornándose solamente armas, armas del ejército en particular. El manejo de las armas por la máquina de guerra está relacionado con una "acción libre" y no con un objetivo. En ese sentido, las armas del ejército son más utensilios que armas. El movimiento de los utensilios es relativo a una finalidad. Pero el movimiento de las armas es absoluto, inmanente. La "acción libre" hace de cualquier instrumento un arma -un cartel en una manifestación, el ladrillo de una casa amenazada de desmoronamiento, un concepto filosófico en conexión con un problema urgente, un ready-made al estilo de Duchamp...

Las instrucciones y los manuales son del orden de los utensilios, cuya gravedad exige cuidados y preparativos. El arma está relacionada con un vector de velocidad. Pertenece a un sistema de perpetuum mobile (DELEUZE, 2004: 399). Ya el utensilio atiende a un régimen, a una organización y desarrollo de formas. Tal régimen se opone al régimen afectivo de la máquina de guerra porque no acepta la reducción del trabajo a una acción inmediata. Pretende regularlo con horarios, lugares y jerarquías -toque de queda. Además, un afecto (y un "trabajo afectivo" sigue ese régimen) es una descarga rápida y momentánea, una exteriorización inmediata. Un afecto nunca es afecto de, así como un trabajo no se resume en un trabajo para. Afecto y trabajo son regímenes intensivos en la máquina de guerra. Designan devenires de quien es afectado o trabaja un material cualquiera. Aquí el punto crucial reside en la oposición afecto-sentimiento, aún más que en la posición aparentemente idealista que opone acción libre y trabajo. El afecto es la descarga inmediata de una emoción, la réplica pasional e imprevisible hasta para quien replica, mientras que el sentimiento procede como una emoción siempre retardada, dislocada. He ahí el sentido en que las armas 
son afectos, que permite afirmar que los utensilios serían sentimientos interiorizados como las obligaciones de una vida "bien administrada": la casa con su funcionamiento ideal.

Sin embargo, lo que llamé hasta aquí instrumento para hablar de los objetos o piezas de cada uno de los paradigmas -instrumentos-utensilios del aparato de Estado, instrumentos-armas de máquina de guerranecesitan ser fabricados, forjados. A partir de ahí, el propio proceso de concepción de los utensilios y armas requiere un análisis. Deleuze y Guattari llegan entonces al suelo común de los dos paradigmas afirmando y coronando el principio inmanentista que anima todo el agenciamiento de Capitalismo y Esquizofrenia.

La nueva figura introducida es la figura del "metalúrgico" como intermezzo liso-estriado, espacio "ahuecado" en el que la experimentación de materiales y formas aparecen mezclados, pero que debe ser visto como un primer movimiento de reterritorialización, indicando el pasaje o la transición de todas las formas a su exterior nómada. Esto porque las piezas fabricadas por la metalurgia no obedecen a un molde, sino que son producidas según la "coagulación" instantánea de los materiales trabajados. Por tanto, la metalurgia surge como fuerza creadora capaz de amenazar al aparato de Estado y como límite de ese aparato. Se trata de la proposición VIII ("la metalurgia constituye de por sí un flujo que converge necesariamente con el nomadismo"), que responde al siguiente problema (III): "¿Cómo los nómadas inventan o encuentran sus armas?" (DELEUZE, 2004: 405)

\section{Conclusión: la metalurgia y el combate efectivo}

El problema anunciado más arriba está seguido de un último axioma (III). A su vez, éste está acompañado por una última proposición (IX) al respecto de la noción polémica de "guerra". Tal vez sea más adecuado concluir este breve comentario con un abordaje directo del axioma y la proposición. Sin embargo, prefiero concluir con un "gancho", artificial y tal vez indebido, entre el uso que Deleuze y Guattari hacen del fenómeno de la metalurgia y 
el problema de la lucha (micro) política. El motivo es simple: la metalurgia acaba siendo la mejor "ilustración" de las características nómadas, sin negar, sin embargo, su proximidad con la forma-Estado.

Es en ese sentido que debemos intentar comprender la idea del axioma III, según el cual la máquina de guerra es una forma de expresión correspondiente a la forma de contenido del metalúrgico. Se trata de explicitar el hecho de que los dos paradigmas están en una relación de presuposición recíproca, pero que es la metalurgia la que desempeña el papel de "estado de cosas" proporcionando una acción de tipo máquina de guerra. La importancia de ese gesto casi final de los autores consiste en contornear cualquier idealismo que los convoque a todos para una celebración de la máquina de guerra como constitutiva absoluta del aparato de Estado, precisamente a partir de la asociación del primer paradigma con el devenir -sólo habría devenir, no pasando el ser de una derivación... Sin embargo, aquí vemos que el suelo común que comunica al aparato de Estado y la máquina de guerra es la metalurgia. No hay una vida-devenir, como pueden pensar los adeptos de una univocidad de destino, distensionada y abstracta, sino devenires completos que son límites o puntos de fuga de formas relativamente estables: devenires siempre minoritarios pero inseparables de un contexto macro... He ahí porque no hay devenir de lo que ya conquistó históricamente lugar... Pero tampoco hay devenir separado de esa lucha que eventualmente lleva a la formación de una mayoría, a un nuevo patrón o modelo. Devenir-mujer, devenir-homosexual, devenir-negro, devenir-niño... eso sí, todos siempre indisociables de un movimiento de resistencia "metalúrgica". Pero no devenir-hombre, devenir-heterosexual, devenir-blanco, devenir-adulto y ni siquiera desconectados de la historia. No hay ontología que no sea, desde el principio, ética y política.

Por tanto, la metalurgia traduce la tensión entre los dos polos paradigmáticos discutidos, afirmando la fuga de las capturas promovidas por el aparato de Estado, pero sin remitir a un afuera absoluto que pudiera hacer creer en un punto de ruptura total, en una fuga hacia lo imaginario o en una posición de retirada "a lo Heidegger". Tal vez el metalúrgico sea Maiakovski o Brecht, freudismo y marxismo, el levantamiento 
de Potemkin y la independencia de los Estados Unidos. Le sirve tanto a la máquina de guerra como al aparato de Estado. Y es verdad que su práctica de creación no implica un telos. Sin embargo, los objetos fabricados acaban destinándose a algo específico. El metalúrgico trabaja para el establecimiento de un modo de vida. Y es más cierto aún que el metalúrgico borra la extensión en favor de materias-flujos intensivos como el nómada. Pero elimina ese espacio extensivo únicamente por una supresión de la distancia entre él y la materia. En todo caso él permanece como "doble", comunicado con sedentarios y nómadas (DELEUZE, 2004: 406), pues los paradigmas que emergen de la acción de esos grupos (el aparato de estado y la máquina de guerra) están lejos de expresar cualquier moral o ideología política. Apenas indican movimientos de aceleración y lentitud, característicos de la vida individual y colectiva. No representan izquierda o derecha, demócratas del voto o monarquías, parlamentaristas o presidencialistas, sociedades primitivas o modelo político griego/moderno, agentes en contra o a favor de la globalización, movimientos sociales organizados o incluso -como los términos pueden sugerir- tendencias de estatalización o neoliberales. Hay Estados, en el sentido macropolítico, que comportan campos de exterioridad bastante amplios. Hay movimientos sociales que combaten sólo por más zona de influencia. La máquina de guerra no es una bandera de Estado mínimo o por cualquier otro tipo de reivindicación. No es espontaneísta y ni siquiera "democrática". No pasa de un paradigma de creación y de acciones continuas. En la mejor de las hipótesis, es la no-censura, el desbloqueo, el compromiso para hallar una salida, no una solución para problemas naturalizados, sino una salida cuando estos nos sofocan. Pero la salida no es una mera fuga negativa, sino una búsqueda de oxígeno: "un poco de posible para no sofocarnos"9... La fabricación de posibles requiere el trabajo de materiales del metalúrgico, bajo riesgo de transformarse en un posible que es apenas objeto de nuestra imaginación.

Finalmente, lo que parece es que los combates ético-políticos de todos los tiempos sólo ganarían al mantener esas tendencias como un horizonte

$9 \quad$ N. del T. Palabras de Deleuze dedicadas a los últimos trabajos de la vida de Foucault sobre la ética del cuidado de sí como práctica de libertad. 
a ser pensado, tanto para poder escapar del aprisionamiento en un aparato de Estado (una pérdida de velocidad que compromete la creación y la adopción de nuevos modos de vida) como para poder dar consistencia a los movimientos de la máquina de guerra (haciendo que la velocidad no redunde en un caos generalizado).

No se trata por tanto, al modo brasilero, de estar en contra o a favor, de esto o de aquello, sino de ver como eso o aquello son forjados. Tal vez se trata de una atención redoblada al trabajo de metalurgia, que involucra la fabricación de nuevos instrumentos: armas para el combate y la reinvención del socius, pero también utensilios para su manutención, dependiendo de los agenciamientos de deseo que seamos capaces de engendrar.

\section{Bibliografía}

Deleuze, Gilles, y Félix Guattari. Mil Mesetas. Capitalismo y Esquizofrenia. José Vásquez Pérez y Umberlina Larraceleta (Trads.). Valencia: PreTextos, 2004. 